\title{
Molecular Cloning and Sequencing of General Odorant-binding Proteins GOBP1 and GOBP2 from the Tobacco Hawk Moth Manduca sexta: Comparisons with Other Insect OBPs and Their Signal Peptides
}

\author{
Richard G. Vogt, ${ }^{1}$ Robert Rybczynski, ${ }^{2}$ and Michael R. Lerner ${ }^{2}$ \\ 'Department of Internal Medicine and ${ }^{2}$ Howard Hughes Medical Institute, Department of Internal Medicine, Yale University \\ School of Medicine, New Haven, Connecticut 06510
}

Odorant-binding proteins (OBPs) are small, water-soluble proteins uniquely expressed in olfactory tissue of insects and vertebrates. OBPs are present in the aqueous fluid surrounding olfactory sensory dendrites and are thought to aid in the capture and transport of hydrophobic odorants into and through this fluid. OBPs may represent the initial biochemical recognition step in olfaction, because they transport odorants to the receptor neurons. Insect OBPs are represented by multiple classes: pheromone-binding proteins (PBPs) and general odorant-binding proteins (GOBP1 and GOBP2). PBPs associate with pheromone-sensitive neurons, while GOBPs associate with general odorant-sensitive neurons. Analysis of $\mathrm{N}$-terminal amino acid sequences of 14 insect OBPs isolated from six species indicated that the PBPs were variable and the GOBPs were highly conserved. However, inferred properties of these proteins were based only on partial sequence data. We now report the full-length sequences of a GOBP1 and GOBP2 from the moth Manduca sexta and compare these sequences with those of PBPs from three species, including $M$. sexta, Antheraea polyphemus, and A. pernyi. We also compare these with a GOBP2 of $A$. pernyi, previously identified only as a novel OBP. These comparisons fully support our $\mathrm{N}$-terminal analysis. The signal peptide sequences of seven insect OBPs reveal conserved sequences within OBP classes, but not between OBP classes even within the same animal species. This suggests that multiple OBPs may be coexpressed in the same cell type, but differentially processed in a class-specific manner. Properties of the GOBPs suggest that general olfaction is broadly receptive at the periphery. Properties of the PBPs suggest that pheromone olfaction is discriminatory at the periphery, and that the initial biochemical steps in pheromone detection may play an active role in odor perception.

The odorant-binding proteins (OBPs) of insects represent a multigene family of lipid carriers that are uniquely expressed in olfactory tissue (Vogt et al., 1991). They reside in the aqueous

\footnotetext{
Received Mar. 1, 1991; accepted Apr. 16, 1991.

We thank Dr. H. Breer for supplying a preprint of Krieger et al. (1991) and Ms. S. Staurovsky for technical assistance. Support was provided by NIH Grant RO1NS27086 (R.G.V.) and HHMI (M.R.L.).

Correspondence should be addressed to Richard G. Vogt, Ph.D., Department of Biological Sciences, University of South Carolina, Columbia, SC 29208.

Copyright (c) 1991 Society for Neuroscience 0270-6474/91/112972-13\$05.00/0
}

fluid surrounding the dendrites of the olfactory neurons and are presumably expressed in and secreted by the glia-like support cells that ensheathe the neuronal somata. The proposed function of these OBPs is to solubilize and transport hydrophobic odorants into and through the aqueous fluid surrounding olfactory dendrites. The most thoroughly described members of this group are the pheromone-binding proteins (PBPs), identified and either partially or fully sequenced from seven moth species (Vogt and Riddiford, 1981a,b; Gyorgyi et al., 1988; Raming et al., 1989, 1990; Vogt et al., 1989, 1991; Breer et al., 1990). Fulllength cDNA sequences have been obtained for PBPs of the tobacco hawk moth Manduca sexta (Gyorgyi et al., 1988) and the giant silk moths Antheraea polyphemus (Raming et al., 1989) and $A$. pernyi (Raming et al., 1990). The PBPs are about 16 $\mathrm{kDa}$, are freely water soluble, exist at concentrations in vivo of about $10 \mathrm{~mm}$ (Klein, 1987), and probably exist as homodimers (De Kramer and Hemberger, 1987).

Besides the PBPs, two additional classes of insect OBP have been described: the general odorant-binding proteins GOBP1 and GOBP2 (Vogt et al., 1991). PBP, GOBP1, and GOBP2 are all expressed in the same individual species, but the GOBPs show a pattern of expression distinctly different from the PBPs. While the PBPs are largely male specific, associating with pheromone-specific sensory neurons, the GOBPs are present in both sexes, associating with olfactory neurons thought to respond to general odorants.

A striking feature of difference between the PBPs and the GOBPs is the degree to which their respective sequences vary when compared between species: the PBPs are variable, while the GOBPs are highly conserved. N-terminal amino acid sequences of seven PBP, five GOBP2s, and two GOBP1s were compared among six moth species (Vogt et al., 1991). The PBPs of different species showed a high degree of variability, with identity values ranging from 0.32 to 0.77 , depending on which two PBPs were compared. The identity values relate to the number of same amino acids per position over the determined sequence, such that a score of 1.0 would indicate the same exact sequence. In contrast to the PBPs, the GOBPs showed a much higher degree of conservation among the same moth species, with identity values ranging from 0.93 to 1.0 . The three classes of OBP were distinctly different from each other in their overall sequence motifs, with between-class identity value ranges of $0.26-0.57$ (PBP vs. GOBP2), $0.21-0.46$ (PBP vs. GOBP1), and $0.47-0.57$ (GOBP1 vs. GOBP2). 
I wo features can be inferred from these variation patterns. First, while there is relatively low identity among the three classes, there are conscrved motifs common to all three groups. Thus, the three classes are presumed to be derived from distinctly different though homologous genes, rather than from a common but alternatively processed transcript of a single gene. This view is supported by recent analysis of the genomic organization of the $A$. pernyi PBP gene (Krieger et al., 1991). Second, the sequence differences between the three OBP classes suggested that PBP, GOBP1, and GOBP2 bind different classes of odorant molecules. Specific odorant-binding properties implied that the OBPs act as odorant filters peripheral to the receptors, since the OBPs are situated between the external environment and the sensory neurons.

These inferences were based on comparisons of only a relatively small part of the OBPs, about one-fifth their overall length. Since it was possible that this $N$-terminal variation would not extend to the rest of the protein, we have now obtained fulllength scquences of the $M$. sexta GOBPl and GOBP2 through cDNA cloning. This allows for comparison of the full amino acid sequences of all three classes of OBP from a single species, as the sequence of the $M$. sexta PBP is also available (Gyorgyi et al., 1988). We are further able to compare the full amino acid sequences of two GOBP2s, as Breer et al. (1990) have recently reported the sequence of a novel class of insect OBP from $A$. pernyi, which can now be identified as a GOBP2. A comparison of the full-length sequences of three PBPs, two GOBP2s, and one GOBPl supports our N-terminal analysis of variation and the inferences drawn (Vogt et al., 1991), as well as the importance that conserved cysteine residues and hydrophobic domains may have in the overall structural and functional properties of the proteins (Breer et al., 1990; Raming et al., 1990). Finally, a comparison of seven OBP signal peptides shows a pattern of conservation suggesting that multiple OBP classes may be cocxpressed but independently processed within the same class of sensilla.

\section{Materials and Methods}

Animal tissues. Manduca sexta were reared in our laboratory from embryos at $28^{\circ} \mathrm{C}$ on a $16: 8$-hr light/dark cycle. Embryos were obtained as fertilized eggs from J. Hobgood, USDA Agricultural Research Service, Oxford, NC. Antennal and leg tissues were dissected from preemerged or newly emerged adult male animals and directly frozen at liquid nitrogen temperature. Tissues were stored at $-80^{\circ} \mathrm{C}$ until use.

$R N A$ isolation and $p o l y A^{\prime}$ selection. RNA for library construction and for PCR experiments was isolated from tissue taken from preemerged and newly emerged adult animals. RNA for Northern blot analysis was isolated from tissue taken from newly emerged adults. RNA was isolated by either of two equally suitable methods. By one method, tissue was homogenized in a Brinkman PT 10-35 homogenizer in guanidinium thiocyanate ( $4 \mathrm{~m} ; 25 \mathrm{~mm}$ sodium citrate, $\mathrm{pH} \mathrm{7.0;0.5 \%} \mathrm{sarcosyl;}$ $72 \mu \mathrm{l} / \mathrm{ml} \beta$-mercaptoethanol) and centrifuged briefly to remove debris. The supernatant was overlaid onto a $\mathrm{CsCl}$ pad $(5.7 \mathrm{M} ; 50 \mathrm{~mm} \mathrm{Na}$-acetate) and centrifuged $24 \mathrm{hr}$ at $30,000 \mathrm{rpm}, 20^{\circ} \mathrm{C}$ in a swinging bucket rotor. The resulting RNA pellet was redissolved in RNase-free $\mathrm{H}_{2} \mathrm{O}$ and precipitated in $\mathrm{Na}$-acetate/ethanol. The final pellet was dissolved in RNasefree $\mathrm{H}_{2} \mathrm{O}$ and stored at $-80^{\circ} \mathrm{C}$ as total RNA. Alternatively, tissue was homogenized in the same guanidinium solution in a porcelain mortar and pestle in liquid nitrogen and processed through an acid-phenol extraction and isopropanol precipitation after the method of Chomczynski and Sacchi (1987; Promega Technical Bulletin TBO64:5/88). In either method, no more than $0.1 \mathrm{gm}$ tissue was homogenized per milliliter of guanidinium solution.

Total RNA was polyA selected by affinity chromatography with oligodT cellulose (type 2, Collaborative Research Inc.) following a modified handbook protocol (Davis et al., 1986) where polyA ${ }^{+}$RNA was eluted directly in RNase-free $\mathrm{H}_{2} \mathrm{O}$. RNA was polyA selected twice for cDNA synthesis and once for Northern blot analysis.

Construction of $c D N A$ library. A cDNA library was constructed in LamdaZAP II (Stratagene) from polyA ${ }^{+}$RNA isolated from preemerged and newly emerged adult male $M$. sexta. Blunt-end, double-stranded cDNA was synthesized from $5 \mu \mathrm{g}$ of RNA by a method utilizing RNase H (Gubler and Hoffman, 1983) using a kit (Amersham). EcoRI/NotI linker adapters (Invitrogen) were then ligated to the CDNA, and the product was electrophoresed on a $1.2 \%$ agarose gel along with size markers and visualized with ethidium bromide. The portion of the gel containing DNA greater than 700 base pairs (bp) long was excised, and the cDNA was electroeluted (Invitrogen Geneluter ${ }^{\mathrm{TM}}$ ). Eluted cDNA was phenol-chloroform extracted, precipitated in Na-acetate/ethanol, and ligated onto lamdaZAP II arms, which were then packaged using Gigapack Gold II (Stratagene). This library contained about $10^{7}$ plaque forming units (pfu), of which greater than $90 \%$ contained inserts. A plate-amplified aliquot of the library was used for this GOBP study.

Polymerase chain reactions. Polymerase chain reactions (PCR; Saiki et al., 1985) were done on a Perkin-Elmer Cetus DNA Thermo Cycler. Reaction conditions throughout were as follows: Reactions contained $10 \times$ buffer $(10 \mu \mathrm{l}$ of $500 \mathrm{~mm} \mathrm{KCl}, 25 \mathrm{~mm} \mathrm{MgCl}, 500 \mathrm{~mm}$ Tris $\mathrm{pH} 8.4$, $1 \mathrm{mg} / \mathrm{ml} \mathrm{BSA}$, $1 \%$ Triton X-100), dNTP mix (2 $\mu$ l of a mixture containing $10 \mathrm{~mm}$ of each base in $\left.\mathrm{H}_{2} \mathrm{O}\right)$, sense primer $(10 \mu \mathrm{l}$ of $5 \mathrm{pmol} / \mu \mathrm{l}$ in $\mathrm{H}_{2} \mathrm{O}$ stock), antisense primer ( $10 \mu \mathrm{l}$ of $5 \mathrm{pmol} / \mu \mathrm{l}$ in $\mathrm{H}_{2} \mathrm{O}$ stock), Taq DNA polymerase ( $3 \mathrm{U}$; Promega), and template DNA in $\mathrm{H}_{2} \mathrm{O}$ to a final volume of $100 \mu \mathrm{l}$. The reaction cycle was $94^{\circ} \mathrm{C} / 30 \mathrm{sec}, 52^{\circ} \mathrm{C} / 1 \mathrm{~min}$, $72^{\circ} \mathrm{C} / 3 \mathrm{~min}$ for 35 cycles. The reaction was initiated with a single denaturation step of $94^{\circ} \mathrm{C} / 3 \mathrm{~min}$.

Primers for PCR were degenerate oligonucleotides based on the $\mathrm{N}$-terminal amino acid sequences of $M$. sexta GOBPl and GOBP2 (Table 1; Vogt et al., 1991). Initial PCR studies of GOBP2 used degenerate oligonucleotides based solely on the predicted nucleic acid sequence. For cloning of PCR products, primers were synthesized with an FcoR I recognition sequence, preceded by four dTTPs for the purpose of providing the enzyme with enough DNA to the $5^{\prime}$ side of its site for effective cutting (Table 1 ).

Initial template DNA for PCR was single-stranded cDNA synthesized from oligo-dT-primed RNA (adult female antennal, $0.5 \mu \mathrm{g}$ polyA* reacted with M-MLV $\mathrm{H}^{-}$Reverse Transcriptase; Bethesda Research Laboratories) using buffers and reaction protocols supplied with the enzyme. $\mathrm{RNasin}^{\mathrm{TM}}$ (Promega) was included at $40 \mathrm{U}$ per reaction. Aliquots (1/10) of this reaction mixture were used as template material for the initial PCR reactions. Template DNA for subsequent PCR was either PCR product DNA or pBluescript (Stratagene) containing insert cDNA.

For synthesis of screening probes, PCR-amplified DNA was gel purified and then subjected to a second round of amplification. This second product was gel purified, restriction digested with EcoRI, gel purified again to remove the small end restriction fragments, and then ligated into pBluescript that had been EcoRI digested and dephosphorylated (calf intestinal phosphatase; Maniatis et al., 1982). The plasmid DNA was transformed, by heat shock (Maniatis ct al., 1982), into DH5a competent cells (Clontech), which were prepared after Maniatis et al. (1982). DNA from individual colonies was prepared and sequenced as described below.

To gel purify PCR-amplified DNA, the entire reaction mixture was electrophoresed in an $8 \%$ polyacrylamide gel (PAGE) in TBE ( $89 \mathrm{~mm}$ Tris, $89 \mathrm{~mm}$ boric acid, 2 mm EDTA; Maniatis et al., 1982). The amplified DNA band was visualized by soaking the gel for 5 min in $1 \%$ methylene blue in $\mathrm{H}_{2} \mathrm{O}$, followed by a rinse in $\mathrm{H}_{2} \mathrm{O}$. Further destaining was unnecessary, and the DNA band was excised. DNA was eluted from the excised gel overnight in elution buffer $(0.5 \mathrm{M}$ ammonium acetate, $10 \mathrm{~mm} \mathrm{Mg-acetate,} 1 \mathrm{~mm}$ EDTA, $0.1 \% \mathrm{SDS}$; in a $37^{\circ} \mathrm{C}$ shaking incubator). DNA was precipitated from this solution by addition of $2 \mathrm{vol}$ ethanol (no additional salt) and chilling on dry ice for $30 \mathrm{~min}$. Following centrifugation, the DNA pellet was resuspended in TE $(10 \mathrm{~mm}$ Tris, 1 mM EDTA, pH 7.5) and reprecipitated with Na-acetate/ethanol. The DNA was finally resuspended in TE and stored at $-20^{\circ} \mathrm{C}$.

Labeling of screening probes. Cloned PCR product CDNA was prepared from large-scale plasmid preparations $(500 \mathrm{ml})$ where the DNA was subjected to two rounds of $\mathrm{CsCl}$-gradient centrifugation (Maniatis et al., 1982). Insert cDNA was isolated by EcoRI digestion of the plasmid, followed by purification by PAGE ( $8 \%$, TBE), as described above. Labeled probe was made by filling the EcoRI cut ends with dTTP and ${ }^{32} \mathrm{P}$-dATP using the Klenow fragment of $E$. coli DNA polymerase $\mathrm{I}$. The labeling reactions for the Northern probes were as follows: DNA (25 
ng in $2.5 \mu \mathrm{l} \mathrm{TE}), 10 \mathrm{x}$ Klenow buffer $(2.5 \mu \mathrm{l}$ of $0.5 \mathrm{M}$ Tris-HCl, $\mathrm{pH} \mathrm{7.2,}$ $0.1 \mathrm{M} \mathrm{MgSO}_{4}, 1 \mathrm{~mm}$ dithiothreitol, $\left.500 \mu \mathrm{g} / \mathrm{ml} \mathrm{BSA}\right)$, dTTP (2 $\mathrm{nmol}$ in $\mathrm{H}, \mathrm{O}),{ }^{32} \mathrm{P}-\mathrm{dATP}(45 \mu \mathrm{Ci}, 3000 \mathrm{Ci} / \mathrm{mmol}$; Amersham), Klenow (2.5 U), and $\mathrm{H}_{2} \mathrm{O}$ to $25 \mu \mathrm{l}$. The entire $25 \mu \mathrm{l}$ reaction was used, with no further cleanup, in $10 \mathrm{ml}$ of hybridization solution. The labeling of probe for library screening differed from the above only in scale, with reactants adjusted proportionally to a final volume of $92 \mu$ l containing $80 \mathrm{ng}$ of DNA, and this probe was divided for use in two $40 \mathrm{ml}$ hybridizations. Aliquots of probes were examined by PAGE ( $8 \%$, TBE) prior to use, and probes were stored at $-20^{\circ} \mathrm{C}$ until use.

Northern blot analysis. PolyA-selected RNAs ( $1 \mu \mathrm{g} / \mathrm{lane})$ from adult male antenna and legs were electrophoresed on a $1.5 \%$ agarose gel containing formaldehyde, along with RNA size markers. RNA was then transferred to Nylon membrane for $4 \mathrm{hr}$ in $0.5 \times \mathrm{TE}$ using a vacuum blutter (LKB Vacugene). Transferred RNA was UV cross-linked to the membrane (Stratalinker, Stratagene). The portion of the membrane containing size-marker RNA was cut away, stained with $1 \%$ methylene blue, and destained with $\mathrm{H}_{2} \mathrm{O}$ to visualize the RNAs. Prehybridization, hybridization, and washes were as described below for library lifts. The prehybridization and hybridization volumes were $10 \mathrm{ml}$, and membranes were processed in sealed plastic bags. Membranes were exposed to $\mathrm{x}$-ray film (Kodak X-OMAT AR) at $-80^{\circ} \mathrm{C}$ for $8 \mathrm{hr}$.

Lihrary screening and sequencing of selected clones. LamdaZAP II were plated with $E$. coli XL1-blue (Stratagene) on $15-\mathrm{cm}$ plates at a density of 15,000 pfu per plate, three plates for each GOBP. Phage DNA was transferred to replicate nylon membranes (ICN), and the DNA was UV cross-linked to the membranes (Stratalinker, Stratagene) following denaturation. Membranes were prewashed for $10 \mathrm{~min}(5 \times$ SSPE), prehybridized $6 \mathrm{hr}$ at $45^{\circ} \mathrm{C}(5 \times$ Denhardt's, $5 \times \mathrm{SSPE}, 0.2 \% \mathrm{SDS}, 0.05 \mathrm{mg} /$ $\mathrm{ml}$ salmon sperm DNA), and hybridized $16 \mathrm{hr}$ at $45^{\circ} \mathrm{C}$ (same as prehybridization solution with formamide added to $50 \%$ ). Membranes were then washed twice in $2 \times \mathrm{SSC}, 0.1 \% \mathrm{SDS}$ at $20^{\circ} \mathrm{C}$; twice in $0.2 \times \mathrm{SSC}$, $0.1 \%$ SDS, $20^{\circ} \mathrm{C}$; twice in $0.2 \times \mathrm{SSC}, 0.1 \% \mathrm{SDS}, 60^{\circ} \mathrm{C}$. Filters were wrapped in plastic and exposed to X-ray film (Kodak X-OMAT AR) at $-80^{\circ} \mathrm{C}$ for $4 \mathrm{~d}$. Recipes for Denhardt's, SSPE, and SSC were from Maniatis et al. (1982).

In the primary screen, about $0.5 \%$ of the plaques were positive for GOBP1 or GOBP2. For each GOBP probe, 20 plaques were isolated and stored at $4^{\circ} \mathrm{C}$ in $\mathrm{SM}(20 \mathrm{~mm}$ Tris- $\mathrm{HCl}, \mathrm{pH} 7.4 ; 100 \mathrm{~mm} \mathrm{NaCl} ; 10$ mM $\mathrm{MgSO}_{4} ; 0.1 \%$ gelatin) containing chloroform. Ten plaques isolated in each first-round screen were rescreened at a density of about $500 \mathrm{pfu}$ per $15 \mathrm{~cm}$ plate, processed as above but without replicate lifts. Four positive clones were isolated for each primary plaque, and these were designated GOBP1-1 through GOBP1-10 (a-d) and GOBP2-1 through GOBP2-10 (a-d), respectively. All 20 "a" clones were individually plasmid rescued to pBluescript, following supplied protocols (Stratagene), and the clones were further characterized as plasmids in E. coli DH5 $\alpha$.

For PCR characterization of clones, a fraction of an individual colony was suspended in $10 \mu \mathrm{l}$ of $\mathrm{H}_{2} \mathrm{O}$, the PCR reaction mix with appropriate primers was added, and the reaction was run and analyzed as described above (under Polymerase chain reactions). The colony bacteria suspended in $\mathrm{H}_{2} \mathrm{O}$ were denatured in reaction tubes prior to addition of the PCR reagents: $60^{\circ} \mathrm{C} / 3 \mathrm{~min}, 80^{\circ} \mathrm{C} / 3 \mathrm{~min}, 94^{\circ} \mathrm{C} / 3 \mathrm{~min}, 4^{\circ} \mathrm{C}$.

For scquencing, plasmid DNA was prepared by an alkaline lysis minipreparation (Kraft et al., 1988) and subjected to double-stranded sequencing usiing the dideoxynucleotide chain-termination method (Sanger et al., 1977) and modified T7 DNA polymerase (Sequenase ${ }^{\mathrm{TM}}$ sequencing kit, version 2.0 , USB), labeling with ${ }^{35} \mathrm{~S}-\mathrm{dATP}(600 \mathrm{Ci}$ / mmol; Amersham). Sequencing primers were the M13 reverse (5'AACAGCTATGACCATG $3^{\prime}$ ) and -40 (5'GTTTTCCCAGTCACGAC $3^{\prime}$ ) primers, corresponding to sites flanking the polylinker region in pBluescript, and sense and antisense primers ( 20 bases long) corresponding to the $\mathrm{N}$-terminal regions of the respective cDNA species (GOBPl: sense, 5'CACGCTAGGTTTTGGACAGG 3'; antisense, 5' TGTTAACTGACTCTCTTCCC 3'; GOBP2: sense, 5'CCATGTTACGGCGCATTTG $3^{\prime}$; antisense, 5'ACCTCCACTGGCAGTCCTGA 3'). The N-terminal primers were designed based on the sequences of the respective PCR-derived screening probes (indicated by position in Fig. 3). Because of the small sizes of the inserts (around $700 \mathrm{bp}$ ), no additional manipulations were necessary to obtain full-length sequences.

$R N A$ transcription and in vitro translation. Plasmid DNAs for clones GOBP1-8 and GOBP2-7 were each linerized with the restriction enzyme Hind III, which uniquely cut each plasmid in the polylinker region at the $3^{\prime}$ end of each insert. One microgram of each DNA was transcribed into RNA using T3 RNA polymerase in the presence of a capping analog
(Stratagene RNA Transcription Kit). The reaction was modified by incubating for $2 \mathrm{hr}$ in the presence of RNasin ${ }^{\mathrm{TM}}$ (Promega; $40 \mathrm{U} / \mathrm{re}$ action), with an additional aliquot of polymerase added after $1 \mathrm{hr}$. RNA was extracted twice with phenol/chloroform/isoamyl alcohol and once with chloroform/isoamyl alcohol and precipitated with $\mathrm{NaCl} /$ ethanol. Aliquots of the transcribed RNA were analyzed by formaldehyde gel electrophoresis and by UV spectroscopy. One-third of each transcribed RNA (about $4 \mu \mathrm{g}$ ), and $\mathrm{H}_{2} \mathrm{O}$ as control, was translated into protein in vitro using rabbit reticulocyte lysate (Promega) in the presence of ${ }^{35} \mathrm{~S}$ methionine (Tran ${ }^{35} \mathrm{~S}-\mathrm{Label}, 1000 \mathrm{Ci} / \mathrm{mmol}, \mathrm{ICN}$ ) and RNasin ${ }^{\mathrm{TM}}$ (Promega) (Vogt et al., 1989). Aliquots (1/25) of each reaction were analyzed by SDS-PAGE (15\%) (Laemmli, 1970), along with molecular-weight markers (BioRad). The gel portion containing the marker lane was excised, and the protein bands were visualized by staining with Coomassie bluc. The gel portion containing the translation products was fixed 30 min in $6 \%$ formaldehyde, soaked $60 \mathrm{~min}$ in $1 \mathrm{M}$ sodium salicylate (Chamberlain, 1979), rinsed briefly in $\mathrm{H}_{2} \mathrm{O}$ to remove surface salicylate crystals, and dried in vacuo. The gel was then exposed to preflashed $\mathrm{x}$-ray film (Kodak X-OMAT AR) at $-80^{\circ} \mathrm{C}$ for $4 \mathrm{hr}$.

Analysis of $c D N A$ sequences. Analysis of cDNA sequences, including Kyte-Doolittle (Kyte and Doolittle, 1982) hydropathy analysis, was done using DNASIS (version 6.00) and PROSIS (version 6.00) computer programs (Hitachi Software Engineering Co., Inc.).

\section{Results}

\section{$P C R$ amplification of GOBP2 and GOBPI CDNA}

We began our study with GOBP2, designing degenerate PCR priming oligos based on the known $\mathrm{N}$-terminal amino acid sequence of this protein (Table 1; Vogt et al., 1991). Primer sites were chosen to make two sizes of product from the GOBP2 cDNA template (Fig. 1). Furthermore, to reduce the degeneracy level for the probes GOBP2-1-sense and GOBP2-2-antisense, two and four forms, respectively, were synthesized, each containing different sequences based on specific amino acid codon choices (Table 1, Fig. 1). These probes were then used to amplify GOBP2 cDNA from a pool of cDNAs synthesized from total antennal RNA ( $1 \mu \mathrm{g})$. Criteria for successful amplification were that both the short and the long product were made (Fig. 1), that both products were specifically generated from antenna cDNA compared with leg cDNA (data not shown), and that one member of the mixed primer sets worked the best. The reaction did produce the predicted size DNAs (Fig. 1). Only reactions primed with GOBP2-1a-sense yielded the predicted bands (data not shown). All of the GOBP2-2-antisense primers were effective, but GOBP2-2d-antisense was the most effective (data not shown).

We then redesigned two of the GOBP2 primers to contain the recognition sequence for the restriction enzyme EcoRI at the 5 ' end of the primer. The sequences of these primers, GOBP2la-sense(EcoRI) and GOBP2-3-antisense(EcoRI), are shown in Table 1 . These two primers were equally effective as their nonappended analogs at amplifying GOBP2 cDNA.

For GOBP1, only two degenerate oligonucleotides were designed, based on the known $\mathrm{N}$-terminal amino acid sequence of this protein (Vogt et al., 1991), GOBPl-sense(EcoRI) and GOBPl-antisense(EcoRI) (Table 1). These primers contained the EcoRI recognition scquence and were effective at amplifying GOBP1 cDNA, based on predicted product size, from a pool of cDNAs synthesized from total antennal RNA (Fig. 1).

\section{Northern blot analysis}

Northern blot analysis was performed to determine GOBP2 and GOBP1 message size and to determine appropriate prehybridization/hybridization/wash conditions for processing nylon lifts during library screening. Probes for GOBP1 and GOBP2 both 


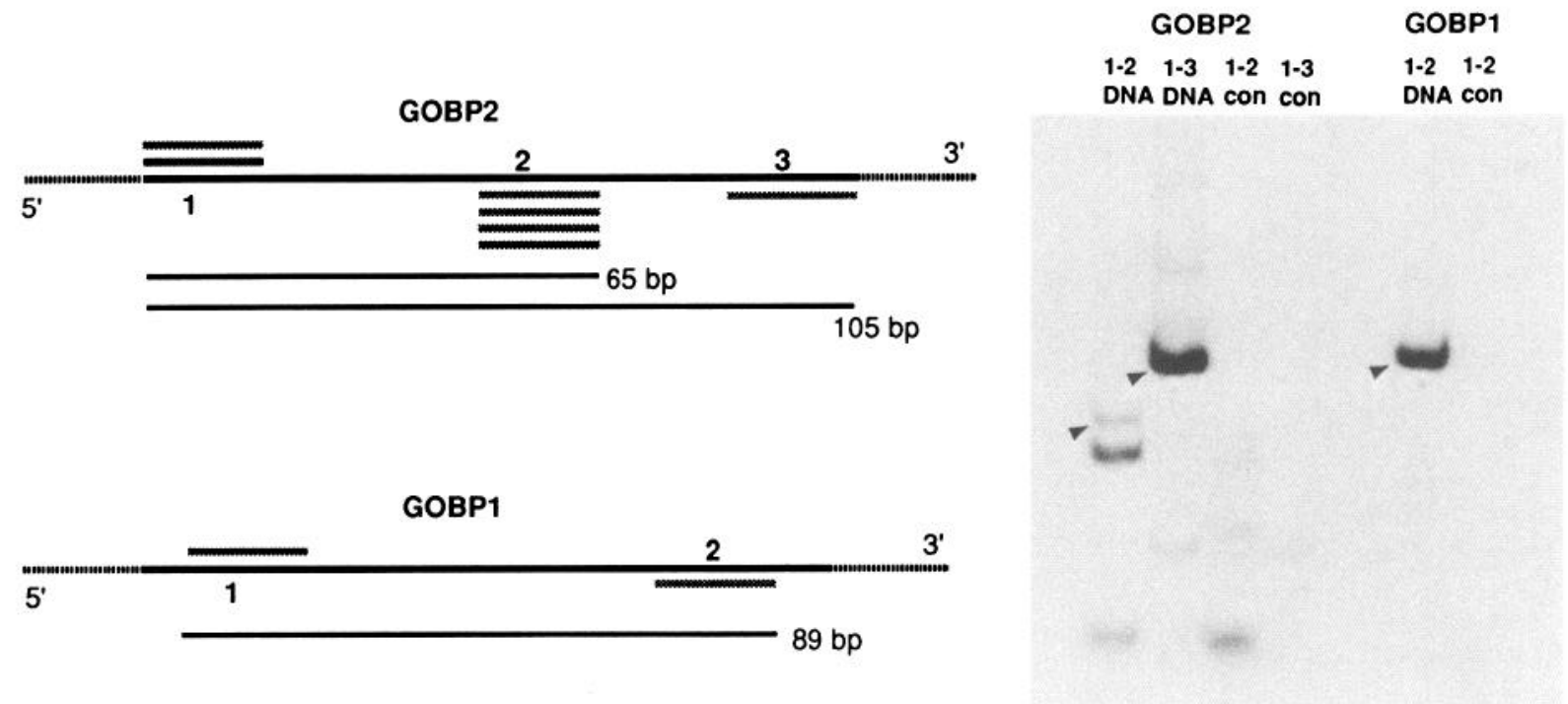

Figure 1. Strategy for amplifying N-terminal nucleic acid sequences of GOBP1 and GOBP2 utilizing PCR. Short bars above lines indicate positions of sense primers; short bars below lines indicate positions of antisense primers. Multiple bars indicate multiple oligos to same amino acid sequence but with limited degeneracy (see Table 1). Predicted product sizes are indicated in base pair $(b p)$ length. An autoradiogram of an $8 \%$ PAGE gel of the PCR products of these reactions is shown. Numbers over lanes indicate primer pairs used. DNA and con indicate source of template: $c D N A$ or control $\left(\mathrm{H}_{2} \mathrm{O}\right)$, respectively. Arrowheads indicate correct products.

recognized RNAs of about 700 base length (Fig. $2 A$ ). Both RNAs were specific to antennal RNA, relative to leg RNA. This relatively small GOBP mRNA size is in contrast with the PBP mRNA size, which was about 1.4 kilobases $(\mathrm{kb})$ for $M$. sexta (Gyorgyi et al., 1988) and A. polyphemus (Raming et al., 1989).

\section{Library screening}

An amplified cDNA library in LamdaZAP II, containing cDNAs of preemerged and newly emerged adult male antennae, was screened with the GOBP1 and GOBP2 probes. Ten clones from each screening were converted to pBluescript by plasmid rescue. Plasmid DNAs were subjected to PCR using the appropriate GOBP1 and GOBP2 EcoRI primers, and all were positive based on amplification of predicted size DNA (data not shown). DNAs were digested with EcoRI and analyzed for size on a $1.2 \%$ agarose gel (data not shown). Insert sizes ranged from around 600 bp to around $1500 \mathrm{bp}$, where the larger ones presumably contained more than one cDNA species. DNAs derived from several clones containing inserts in the size range of $600-900 \mathrm{bp}$ were sequenced.

\section{cDNA and inferred amino acid sequences of GOBPI and GOBP2}

The sequences of two insert cDNAs, GOBP1-8 and GOBP2-7, are shown in Figure 3, along with the inferred amino acid sequences. Numbering of nucleotides begins with number 1 at the

Table 1. Sequences of oligonucleotides used as PCR primers

Oligonucleotide

GOBP2-1a-sense

GOBP2-1b-sense

(TAEVMS)

GOBP2-2a-antisense

GOBP2-2b-antisense

GOBP2-2c-antisense

GOBP2-2d-antisense

(EESREE)

GOBP2-3-antisense

(MDEFKH)

GOBP2-1a-sense(EcoRI)

(TAEVMS)

GOBP2-3-antisense(EcoRI)

(MDEFKH)

GOBP1-sense(EcoRI)

QVMKDV)

GOBP1-antisense(EcoRI)

(EEKMEE)
Sequence

AC(AGCT)GC(AGCT)GA(AG)GT(AGCT)ATGAG

AC(AGCT)GC(AGCT)GA(AG)GT(AGCT)ATGTC

TC(TC)TC(TC)CT(GA)CT(TC)TC(TC)TC

TC(TC)TC(TCGA)CG(TCGA)GA(TC)TC(TC)TC

TC(TC)TC(TC)CT(TCGA)GA(TC)TC(TC)TC

TC(TC)TC(TGCA)CG(GA)CT(TC)TC(TC)TC

GTG(TC)TT(GA)AA(TC)TC(GA)TCCAT

TTTTGAATTCAC(AGCT)GC(AGCT)GA(AGCT)ATGAG

TTTTGAATTCGTG(TC)TT(GA)AA(TC)TC(GA)TCCAT

TTTTGAATTCCA(AG)GT(AGCT)ATGAA(AG)CA(CT)GT

TTTTGAATTCTC(TC)TCCAT(TC)TT(TC)TC(TC)TC

Amino acid sequences corresponding to oligonucleotide sequences are indicated in parentheses below oligonucleotide names; see Figure 4 for single- to triple-letter amino acid code conversions. 
Figure 2. GOBP1 and GOBP2 mRNA $(A)$ and proteins $(B) . A$ represents a Northern blot analysis of GOBP1 and GOBP2 (autoradiogram). Each lane contained $1 \mu \mathrm{g}$ polyA ${ }^{+}$RNA from adult male antenna $(A)$ or leg $(L)$. Each pair of lanes was probed with either GOBP1 or GOBP2 DNA probe. RNA ladder is indicated in kilobase $(k b)$ units. $B$ represents in vitro translations of RNA transcripts of clones GOBP1-8 $(1-8)$ and GOBP2-7 (2-7; fluorogram of $15 \%$ SDSPAGE). Lane $O$ is control reaction with no added RNA. Molecular-weight markers are in kilodalton $(k D a)$ units.

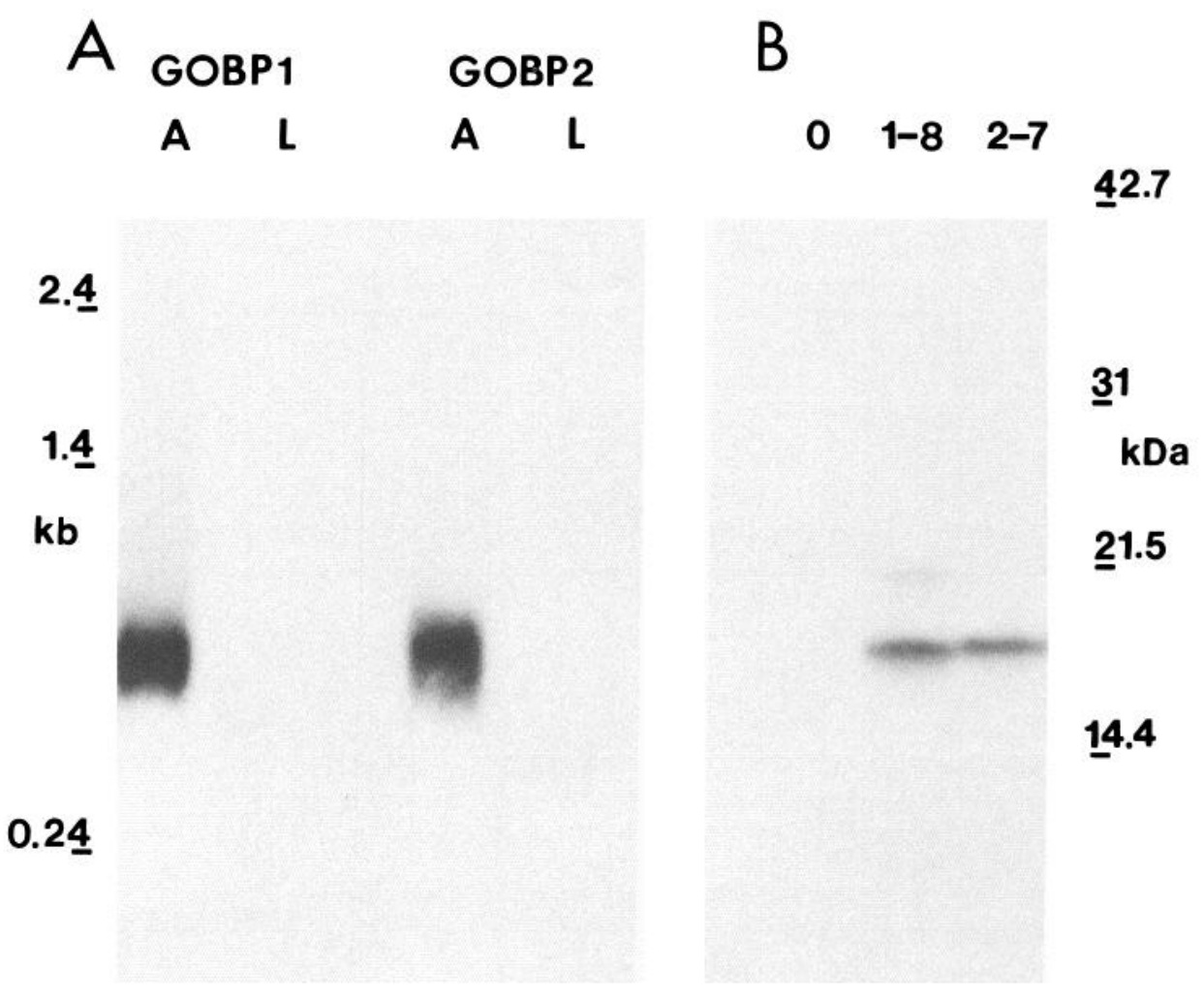

presumed translational start codons. The previously derived $\mathrm{N}$-terminal amino acid sequences for GOBP1 and GOBP2 suggest that the cDNA sequences encoding the initial amino acids of the mature proteins start at positions 67 and 61 , respectively. Open reading frames extend forward to a stop TGA at position 499 in GOBP1-8 and a stop TAA at position 484 in GOBP27. Thus, the mature protein of GOBP1 is estimated to be 144 amino acids in length (MW, $16.9 \mathrm{kDa}, 19.1 \mathrm{kDa}$ including signal peptide), and that of GOBP 2 is estimated to be 141 amino acids (MW, $16.2 \mathrm{kDa}, 18.5 \mathrm{kDa}$ including signal peptide). The cDNA derived amino acid sequence revealed two errors in the previously reported N-terminal sequences (Vogt et al., 1991): positions 19 of both $M$. sexta GOBP1 and GOBP2 are cysteines.

As both GOBP1 and GOBP2 are apparently secreted proteins, we expected that their mRNAs would encode signal peptides for cross-membrane translocation. The initial amino acid codon of each mature protein is preceded by an open reading frame encoding peptides characteristic of signal sequences (von Heijne, 1986; Rapoport, 1990). An in-frame ATG is present as a potential translational start site about 20 codons $5^{\prime}$ of the codons for the first amino acids of the mature proteins. Furthermore, the encoded amino acid sequence of these signal peptides has characteristic central hydrophobic domains, flanked by relatively hydrophilic regions (Figs. 3, 4).

Both GOBP1-8 and GOBP2-7 contain polyadenylated 3 ' tails and are therefore full length at their $3^{\prime}$ ends. GOBP1-8 has an AATAAA 12 bases $5^{\prime}$ of a CA that leads into a polyA stretch. GOBP2-7 has an AGTAAA 13 bases 5' of a CA that leads into a polyA stretch. These sequences are characteristic motifs of polyadenylation signals in eukaryotes (Birnstiel et al., 1985; Sheets et al., 1990; Wickens, 1990). Both insert cDNAs extend only a relatively short distance $5^{\prime}$ of their predicted translational start ATG. This is probably due to the method of second-strand cDNA synthesis employed. In the RNaseH method for priming second-strand synthesis (Gubler and Hoffman, 1983), RNA in the cDNA/RNA hybrid is nicked with $\mathrm{RNaseH}$, and secondstrand cDNA synthesis is primed from the nicked 3' RNA ends. Since there is no primer for the extreme $5^{\prime}$ end of the RNA in this strategy, this region is not preserved and is presumably therefore missing in our inserts. This would be most noticeable for short mRNAs, as in our case, where there was little sequence to begin with $5^{\prime}$ of the start ATGs. The majority of our characterized clones for both GOBP1 and GOBP2 did not in fact contain the translational start ATG, but terminated between the start ATG and the coding region of the $\mathrm{N}$-terminus of the mature protein (the target for our screening probes).

\section{$R N A$ transcription and in vitro translation}

Clones GOBP1-8 and GOBP2-7 were transcribed to RNA, and the RNA was translated to protein by in vitro translation using a rabbit reticulocyte lysate. Translated proteins were examined by SDS-PAGE (Fig. $2 B$ ). The translation of GOBP1-8 appeared as a major band with apparent molecular mass of $18 \mathrm{kDa}$. The translation of GOBP2-7 appeared as a band with apparent molecular mass of $18.5 \mathrm{kDa}$. The apparent masses of both translation products were close to the calculated masses based on amino acid sequence, supporting our interpretations of open reading frames. The slightly smaller than calculated apparent mass of the GOBP1-8 product presumably reflects the imperfectness of determining molecular masses by SDS-PAGE. Both GOBP1-8 and GOBP2-7 appear to be suitable for full-length protein expression, containing functional translation start and stop signals. 


\section{GOBP1-8}

-2 TCATGGGGCAAGACACACGGAGCTTGGTGCTGGTGgTCCTGGTGGGGCTGGTGGGAGCGG $\begin{array}{llllllllllllllllllll}\mathbf{M} & G & Q & \mathrm{D} & \mathrm{T} & \mathrm{R} & \mathrm{S} & \mathrm{I} & \mathbf{V} & \mathbf{L} & \mathbf{V} & \mathbf{V} & \mathbf{L} & \mathbf{V} & \mathrm{G} & \mathbf{L} & \mathbf{V} & \mathrm{G} & \boldsymbol{A} & \mathbf{V}\end{array}$

59 TGTCTGCTGACGTCCAGGTGATGAAGGATGTCACGCTAGGTTTTGGACAGGCGCTAGAAC $\begin{array}{lllllllllllllllllllll}S & A & D & V & Q & V & M & K & D & V & T & \text { L } & G & F & G & Q & A & L & E & Q\end{array}$

119 AATGCAGGGAAGAGAGTCAGTTAACAGAGGAGAAAATGGAGGAGTTCTTCCATTTCTGGC

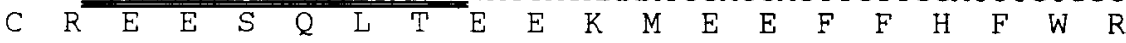

179 GTGAGGACTTCAAGTTCGAGCACCGCGAGTTGGGCTGCGCGCTCCAGTGCATGAGCCGCC $\begin{array}{llllllllllllllllllll}E & D & F & K & F & E & H & R & E & L & G & C & A & L & Q & C & M & S & R & H\end{array}$

239 ACTTCAACCTGCTCACCGACTCCAGCCGCATGCATCACGAAAACACTGACAAGTTCATCA $\begin{array}{llllllllllllllllllll}F & N & L & L & T & D & S & S & R & M & H & H & E & N & T & D & K & F & I & K\end{array}$

299 AATCGTTCCCTAATGGTGCTGTCCTATCAAAGACGATGGTGGAACTTATCCACAATTGTG $\begin{array}{llllllllllllllllllll}S & F & P & N & G & A & V & L & S & K & T & M & V & E & L & I & H & N & C & E\end{array}$

359 AGCTACAACACGACGCAGAAGAGGACCACTGCTGGCGTATCCTCCGAGTGGCGGAGTGCT $\begin{array}{llllllllllllllllllll}L & Q & H & D & A & E & E & D & H & C & W & R & I & L & R & V & A & E & C & F\end{array}$

419 TTAAGATCTCCTGCACGAAGGCTGGCATCGCGCCTTCTATGGAGGTCATGATGGCGGAGT $\begin{array}{llllllllllllllllllll}K & I & S & C & T & K & A & G & I & A & P & S & M & E & V & M & M & A & E & F\end{array}$

479 TCATCATGGAACTGAAACAATGATTCACGAGATTAGGTTAGGGTACAGGGTACAACGGCC

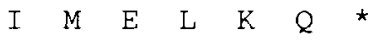

539 TCGCTTTCCGATTGGACGATGTTTTGTTATCAATCAATCAATAAATTATTTGACTGTCAA

599 AAAAAAAAAAAAAAAAAAAAAAAAAAAAAAAAAAAAAAAAAAAAAAAAAAAAAAAAAAA

659 AAAAAA

\section{GOBP2-7}

\footnotetext{
- 16 AgGCAGTGAAGTCGCGATgGTCAACCGGCTGATATTGATGGTCGTGGTTGTGTTCATCAC $\begin{array}{lllllllllllllll}\mathbf{M} & \mathrm{V} & \mathrm{N} & \mathrm{R} & \mathrm{I} & \mathrm{I} & \mathbf{L} & \mathbf{M} & \mathbf{V} & \mathbf{V} & \mathbf{V} & \mathbf{V} & \mathbf{F} & \mathbf{I} & \mathrm{T}\end{array}$

45 TGATTCGGTGATGGGA CAGCAGAGGTGATGAGCCATGTTACGGCGCATTTTGGGAAGGC $\begin{array}{llllllllllllllllllll}D & S & V & M & G & T & A & E & V & M & S & H & V & T & A & H & F & G & K & A\end{array}$

105 GTTAGAGGAGTGTCGGGAAGAGTCAGGACTGCCAGTGGAGGTGATGGATGAGTTCAAACA $\begin{array}{llllllllllllllllllll}L & E & E & C & R & E & E & S & G & L & P & V & E & V & M & D & E & F & K & H\end{array}$

165 CTTCTGGCGCGAGGATTTCGAGGTGGTGCACCGCGAGCTGGGCTGCGCCATCATCTGTAT $\begin{array}{llllllllllllllllllll}F & W & R & E & D & F & E & V & V & H & R & E & L & G & C & A & I & I & C & M\end{array}$

225 GTCCAACAAGTTCGAGCTGCTGCAGGATGATACACGCATCCATCACGTCAAGATGCATGA $\begin{array}{lllllllllllllllllllllll}S & N & K & F & E & L & L & Q & D & D & T & R & I & H & H & V & K & M & H & D\end{array}$

285 T'TATATCAAGAGCTTCCCCAACGGCCAAGTACTATCAGAGAAGATGGTTCAGCTAATTCA $\begin{array}{llllllllllllllllllll}\mathrm{Y} & \mathrm{T} & \mathrm{K} & \mathrm{S} & \mathrm{F} & \mathrm{P} & \mathrm{N} & \mathrm{G} & \mathrm{Q} & \mathrm{V} & \mathrm{L} & \mathrm{S} & \mathrm{E} & \mathrm{K} & \mathrm{M} & \mathrm{V} & \mathrm{Q} & \mathrm{L} & \mathrm{I} & \mathrm{H}\end{array}$

345 CAACTGCGAGAAGCAATACGACGACATCGCGGACGATTGTGACCGCGTGGTTAAGGTTGC $\begin{array}{llllllllllllllllllll}N & C & E & K & Q & Y & D & D & I & A & D & D & C & D & R & V & V & K & V & A\end{array}$

405 AGCCTGCTTCAAGAAGGATGCGAAGAAGGAAGGAATTGCTCCAGAAGTGGCCATGATAGA $\begin{array}{lllllllllllllllllllll}A & C & F & K & K & D & A & K & K & E & G & I & A & P & E & V & A & M & I & E\end{array}$

465 AGCTGTCATCGAGAAGTACTAACCACAACGCATTTGGACACTGATTTAAGTTAAGCATGG $A \quad V \quad I \quad E N \quad K$ *

525 CATGAAAAAAGTAAAAAAAAAAAATGTATCACAATTTGAGTAAATGATTTATGTTTTCAA

585 AAAAAAAAAAAAAAAAA
}

Figure 3. cDNA and inferred amino acid sequences of GOBP1-8 and GOBP2-7. Base position 1 is the A of each translational start ATG (bold and underlined). The initial codon of mature protein is indicated (bold and underlined; GOBP1-8: GAC; GOBP2-7: $A C A$ ). In-frame translational termination codons are indicated in bold, and the presumed utilized termination codons are indicated with asterisks. Polyadenylation signals are underlined (GOBP1-8: AATAAA, CA; GOBP2-7: $A G T A A A, C A$ ). Sequences (cDNA) with heavy underlining and arrows indicate positions and orientations of $\mathrm{N}$-terminal-based sequencing primers. Hydrophobic amino acids in signal sequences are indicated (bold). See Figure 4 for single- to triple-letter amino acid code conversions. GenBank accession numbers: M73797 (GOBP1-8); M73798 (GOBP2-7). 


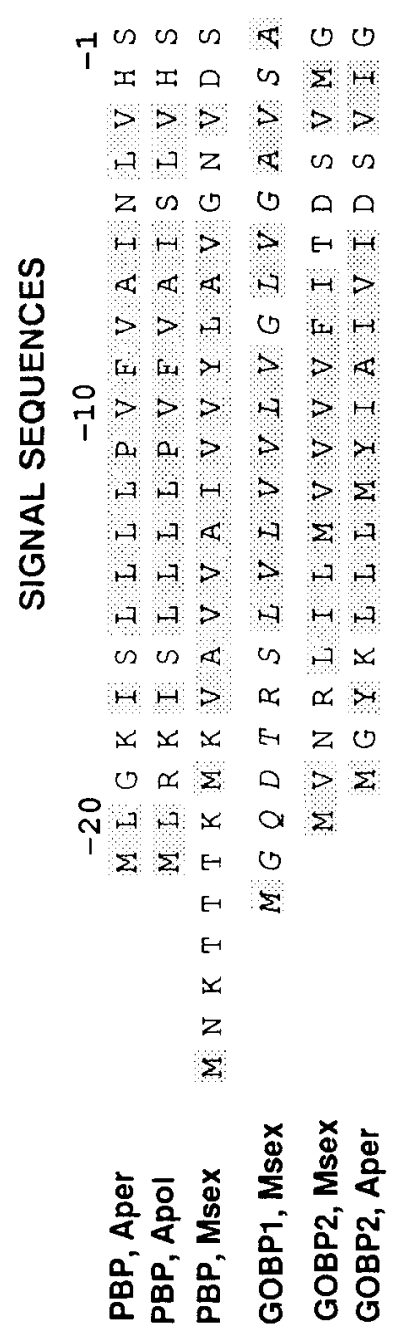

인. $1 \% . \% ० \%$ $\begin{array}{llllll}0 & 0 & 0 & 0 & 0 & 0\end{array}$

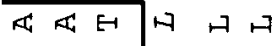

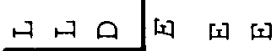

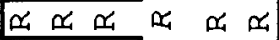

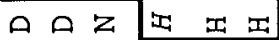
EF $\Sigma \Sigma D \square p$ $>>$ 四这回 年

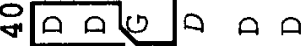
口曰国 国 되 되 $x x>\propto 丿 \omega$ $333 \leq 33$ 近 在 z $z$ I I I

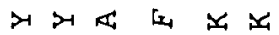
•

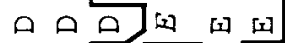
《ब回国层

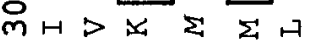
$\Delta>H \gg P$

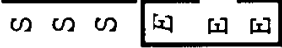
ค口ค国>A

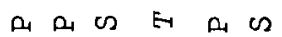
म배배배 z心 $z$ 年 00 म十 $\begin{array}{lll}\text { का } & 0\end{array}$

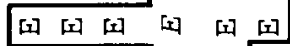

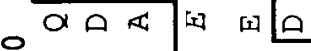

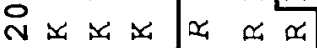
$0 \%$ \% $\%$.

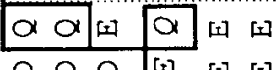
口 0 口我 되 되

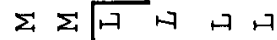
ब《ब ब ब $x x \quad a x x$ $\begin{array}{llllllllllll}0 & 0 & 0 & 0 & 0 & 0 & 0\end{array}$

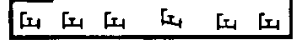

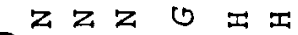
아매셰 कथ $U$ U •

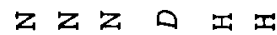
$x x x x \cos$ $H \Sigma \Sigma \Sigma \Sigma \Sigma$ $H H>>>$

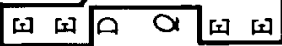
a d a $D$ a 4 H C N U D E E

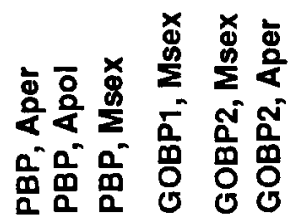

8

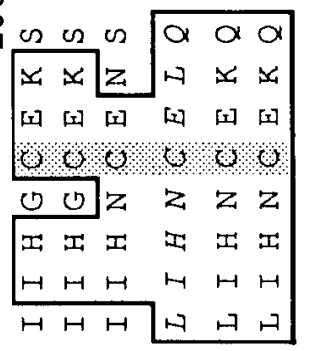

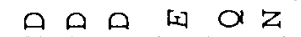
$\Delta>+P>P$ Яㅁㅂ $\Sigma \Sigma \Sigma$ O O O F $\begin{aligned} & \text { a } \\ & \text { a }\end{aligned}$

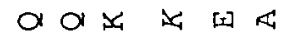
$\varangle \Leftrightarrow \varangle \omega$ $\Sigma \Sigma \Sigma \mapsto \mapsto \mapsto$ D $E \& \triangle P D$

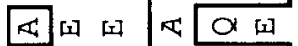
A口ค $\varangle \ll \varangle z z z$

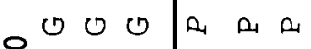

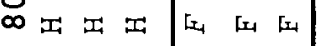

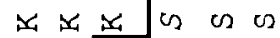
$\Sigma \Sigma \square \quad \square \Sigma$ 《《 《H

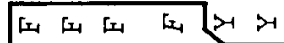

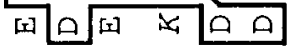

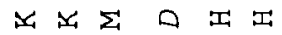
$\varangle \ll \notin E \Sigma$ $\begin{array}{llll}z & z & z & z\end{array} z$

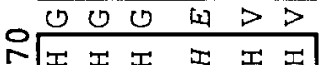

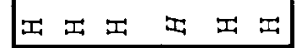
Нナけ $\Sigma H H$

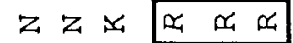
000 ⿰冫 aA口

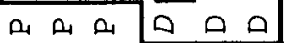
D D A O O Y $>P H A H$ $P>\Sigma H H$

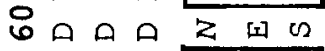

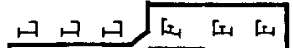

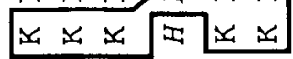
EA E

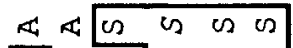
$\Sigma \boxminus \neg \Sigma \Sigma \Sigma$ 0.00000 $Z Z H O H H$

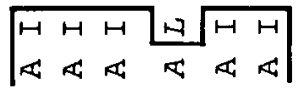

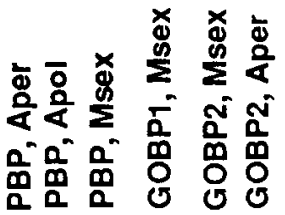

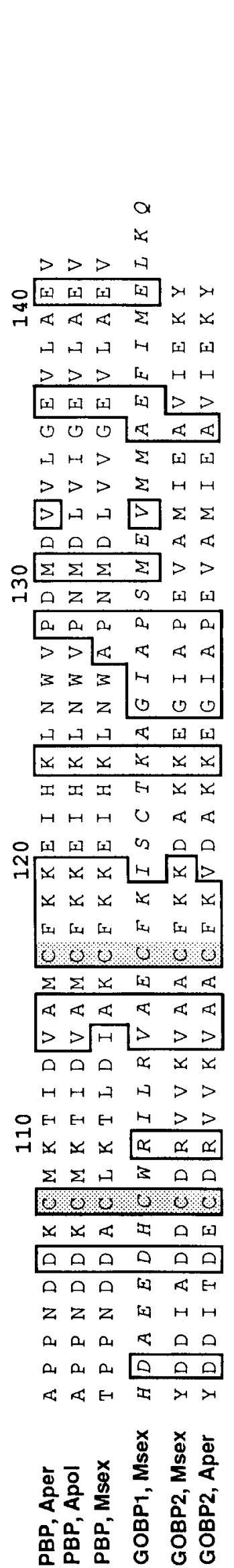

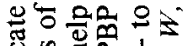

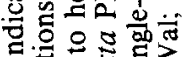

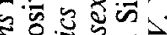

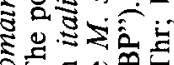

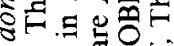

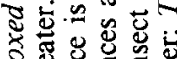

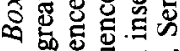
的氞的

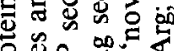

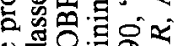

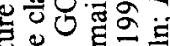
果 0

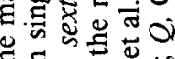

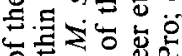

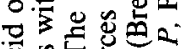
岛 的寅要

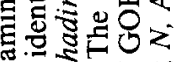

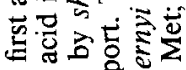
연원

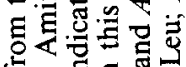
的目 on . 영

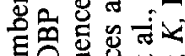

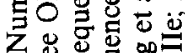

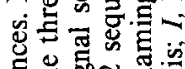

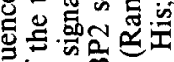

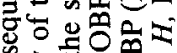

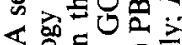

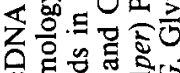
政

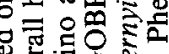
造 w.

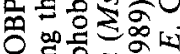

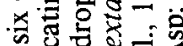
प्यें 政这

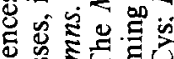

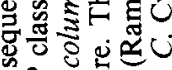

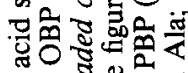

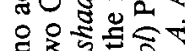

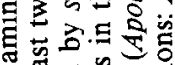

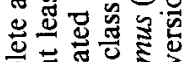
券 듕형몽 응

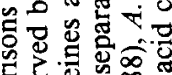
㺃 至的

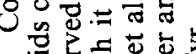
*

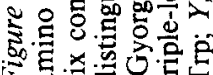




\section{Discussion}

Biochemistry of insect olfaction: PBPs and GOBPS

Insects detect odorants with sensory neurons arrayed along their antennae (Keil, 1984, 1989; Steinbrecht and Gnatzy, 1984). The cell bodies of these bipolar neurons are embedded in the epithelium and ensheathed in specialized glia-like support cells. Axons project inward to the brain, and ciliated dendrites project outward into the external environment. These dendrites are protected from the environment by being encased in hollow cuticular sheaths, the lumen of which is filled with proteinaceous fluid. The entire structure is referred to as a sensillum. Odor molecules are thought to enter a sensillum by passing through pores that penetrate the cuticular sheath. Odors must then enter and pass through the sensillum fluid in order to reach presumed receptor proteins in the dendritic membrane (Vogt et al., 1988).

Terrestrial animals smell odorants that are primarily hydrophobic volatile lipids, in contrast to aquatic animals, which smell odorants that are water soluble, such as amino acids (Carr et al., 1990). In aquatic animals, the odorant molecules have ready access to the sensory neurons, at least with respect to solubility. However, in terrestrial animals there is a hydrophilic barrier to lipid odorants that is situated between the air and the sensory neuron. This barrier is the watery sensilla fluid in terrestrial insects and the watery mucus that covers the olfactory epithelium in terrestrial vertebrates. OBPs have been proposed as agents that help solubilize lipid odorants into and through these watery barriers, allowing the odorants access to dendritic receptor proteins (Vogt et al., 1985; Vogt, 1987; Pevsner et al., 1988a).

OBPs have been identified in several insect (Vogt and Riddiford, 1981a,b; Gyorgyi et al., 1988; Vogt et al., 1989, 1991; Breer et al., 1990; Raming et al., 1990) and vertebrate species (Pelosi et al., 1982, 1990; Lee et al., 1987; Pevsner et al., 1988b). Though the insect and vertebrate OBPs have a similar proposed function (Vogt, 1987; Pevsner et al., 1988a), they are not homologous across phyla (Gyorgyi et al., 1988; Raming et al., 1990). The first insect OBP to be described was the pheromonebinding protein (PBP) of the silk moth Antheraea polyphemus (Vogt and Riddiford, $1981 \mathrm{a}, \mathrm{b}$ ). This $15 \mathrm{kDa}$ protein was present only in male antennal tissue, was shown to be a major component of the extracellular sensilla fluid, and was observed to bind sex pheromone. PBPs have been identified from several additional moth species, including the wild silk moths Antheraea pernyi and Hyalophora cecropia (both Saturniidae), the domestic silk moth Bombyx mori (Bombycidae), the hawk moth Manduca sexta (Sphingidae), and the gypsy moth Lymantria dispar and Douglas fir tussock moth Orgyia pseudotsugata (both Lymantriidae)(Vogt and Riddiford, $1981 \mathrm{a}$; Gyorgyi et al., 1988; Raming et al., 1989, 1990; Vogt et al., 1989). In some species, notably $M$. sexta, PBP is present in both sexes, but levels in the female antennae are comparatively very low (Gyorgyi et al., 1988; Vogt et al., 1991).

Studies of the $A$. polyphemus PBP indicated that it was present in very high concentration, about $10 \mathrm{~mm}$ (Vogt and Riddiford, 1981 b; Klein, 1987), and that it may exist in vivo as a homodimer (De Kramer and Hemberger, 1987). Sex-pheromone binding has been observed by the A. polyphemus PBP (Vogt and Riddiford, 1981b; De Kramer and Hemberger, 1987; Vogt et al., 1988), as well as by the PBPs of $L$. dispar (Vogt et al., 1989). The binding of sex pheromone was suggested to be weak (Vogt and Riddiford, 1986; Vogt, 1987), possibly with a binding con-

\begin{tabular}{|c|c|c|c|c|c|}
\hline & per PB & & & & \\
\hline Apol PBP & 0.91 & Dol PE & & & \\
\hline Msex PBP & 0.65 & 0.67 & Msex $P E$ & & \\
\hline Msex GOBPI & 0.27 & 0.28 & 0.31 & Msex $G$ & $\mathrm{BPI}$ \\
\hline Msex GOBP2 & 0.26 & 0.28 & 0.32 & 0.54 & Msex GOBP2 \\
\hline Aper GOBP2 & 0.26 & 0.28 & 0.31 & 0.52 & 0.87 \\
\hline
\end{tabular}

Fractional values are based on absolute identities only, where a $100 \%$ identity would have a value of 1.00 . Boxed areas indicate comparisons either within or between respective OBP groups. Species abbreviations are as for Figure 4.

stant around $10^{-7} \mathrm{M}$ (De Kramer and Hemberger, 1987). It was proposed that sex pheromone, on entering a sensillum, was solubilized into the sensillum fluid through interaction with PBP (Vogt et al., 1985; Vogt and Riddiford, 1986; Vogt, 1987). In this scheme, sustained PBP-pheromone interactions hold the pheromone in solution long enough for pheromone to migrate to and interact with a receptor protein in the dendritic membrane. Pheromone is thought to be subsequently and rapidly degraded by potent sensilla enzymes (Vogt et al., 1985, 1990; Rybczynski et al., 1989, 1990). Studies of other PBPs have all yielded findings consistent with this view.

Recently, two additional classes of insect OBP have been described (Breer et al., 1990; Vogt et al., 1991). These OBPs had a pattern of expression suggesting that they associate with sensory neurons that detect general odorants and were thus named general odorant-binding proteins (GOBP; Vogt et al., 1991). Unlike the male-specific PBPs, the GOBPs were present in both female and male antennae. Two different GOBPs were successfully isolated from the general-olfactory sensilla of female $M$. sexta antenna (Vogt et al., 1991), and one GOBP was previously observed to bind an odorant (Vogt and Riddiford, $1981 \mathrm{~b}$; Vogt, 1987). Two classes of GOBP were identified based on N-terminal amino acid sequence comparisons: GOBPl and GOBP2 (Vogt et al., 1991). They were designated 1 and 2 based on their relative migration in non-SDS PAGE: GOBP1 migrated slower than GOBP2. All three insect OBPs (PBP, GOBP1, and GOBP2) were coexpressed in the same individual species. The cells that express the OBPs are thought to be the glia-like support cells that ensheathe the sensory neurons and line the base of the sensillum lumen.

$P B P, G O B P 1$, and $G O B P 2$ : comparisons of full-length amino acid sequences

Vogt et al. (1991) compared the N-terminal amino acid sequences of seven PBPs, five GOBP2s, and two GOBP1s. These proteins were isolated from six moth species representing four phyletic families. Sequence motifs were present that indicated that all 14 proteins were homologous. However, sufficient differences exist between the sequences to justify classifying the proteins into three groups. A particularly striking feature was that PBPs showed considerable sequence variation when compared between moth species, while both GOBPI and GOBP2 were highly conserved within their classes and among the same moth species from which the PBPs were compared. However, 
HYDROPHOBIC
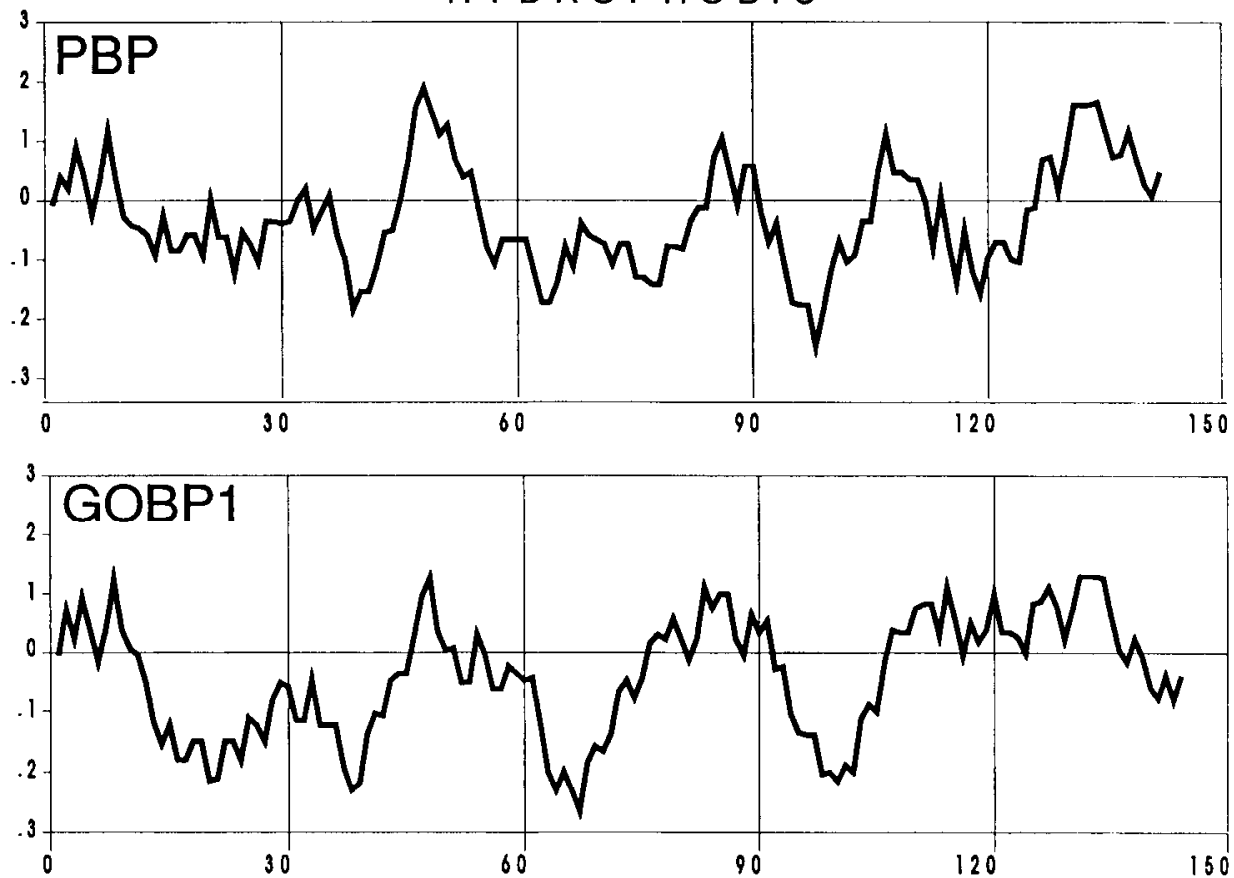

Figure 5. Hydropathy plots (KyteDoolittle) comparing the $M$. sexta PBP, GOBP2, and GOBP1. Window size was nine amino acids. Hydrophobic amino acids were scored positive. Analysis is for mature proteins only, and amino acid positions are indicated on the $x$-axes.

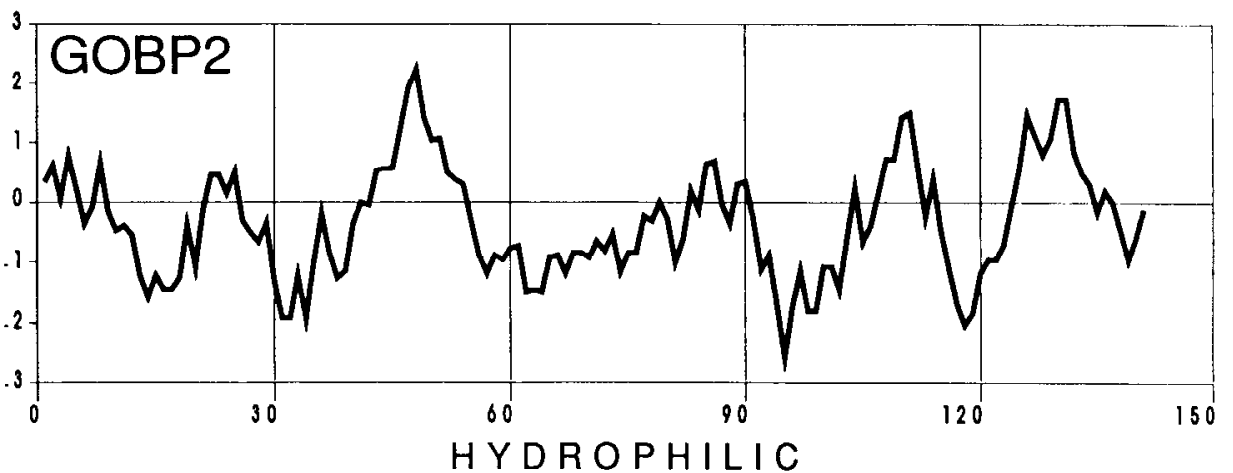

these conclusions were bascd on information derived from relatively small regions of the OBPs, and similar analysis based on full-length sequences was desired.

Full-length sequences of four insect OBPs have previously been reported: the PBPs of $M$. sexta (Gyorgyi et al., 1988), $A$. polyphemus (Raming et al., 1989), and $A$. pernyi (Raming et al., 1990) and a novel OBP from $A$. pernyi (Breer et al., 1990). The novel OBP from $A$. perny $i$ can now be identified as a GOBP2 based on its high degree of sequence identity with the $M$. sexta GOBP2 reported here (Table 2, 0.87). The full-length sequences of these four proteins are presented, together with the sequences of $M$. sexta GOBP1 and GOBP2 of this report, in Figure 4.

The overall homology of the three OBP classes is clearly supported by the boxed domains in Figure 4, where amino acids are boxed if they appear in more than one OBP class at a given position. Pairwise amino acid identity comparisons of the fully sequenced insect OBPs are summarized in Table 2. The PBPs of $A$. polyphemus and $A$. pernyi are nearly identical (0.91), which might be expected of two sibling species that utilize the same chemical pheromone (Kochansky et al., 1975; Meng et al., 1989). Each of the GOBPs is consistently only about $30 \%$ identical to the respective PBPs. The $M$. sexta and $A$. pernyi GOBP2s are nearly identical $(0.87)$, while the PBPs of these same species are much less so $(0.65)$. Both GOBP2s arc about $50 \%$ identical to the $M$. sexta GOBP1.

In general, comparisons of the full-length amino acid sequences of the six insect OBPs fully support our earlier conclusions, which were based solely on $\mathrm{N}$-terminal sequence analysis (Vogt et al., 1991). There are at least three classes of insect OBP: PBP, GOBP1, and GOBP2. Identity comparisons indicate that variation observed in $\mathrm{N}$-terminal regions persists throughout the full lengths of the proteins. Identity values in full-length pairwise comparisons are of similar magnitude to those based on N-terminal sequence alone. Among the same group of species, the PBPs are variable while the respective GOBPs are highly conserved.

Six cysteines have previously been noted to be conserved among the $M$. sexta, $A$. polyphemus, and $A$. pernyi PBPs (Raming et al., 1990) and the novel OBP (GOBP2) of $A$. pernyi (Breer et al., 1990). Breer et al. (1990) suggested that this cysteine conservation could indicate disulfide bridging to maintain threedimensional structure of the proteins and/or possibly to maintain the homodimeric form proposed initially for the $A$. polyphemus PBP (De Kramer and Hemberger, 1987). The $M$. sexta GOBP1 and GOBP2 also contain these six cysteines, indicated in Figure 4 (shaded columns), supporting suggestions that these 


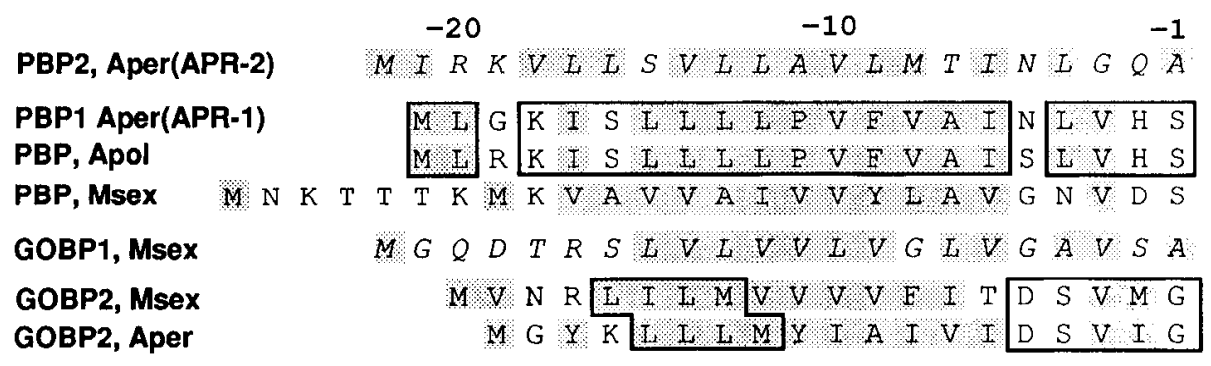

Figure 6. Signal peptide sequences of seven insect OBPs. Shaded regions indicate hydrophobic amino acids. Boxed regions indicate conserved sequences between the PBPs of $A$. polyphemus and $A$. pernyi (APR-1) and between the GOBP2s of $M$. sexta and $A$. pernyi. Two sequences are in italics to help identify them as separate classes in the figure. PBP2, $\operatorname{Aper}(A P R-2)$ is from Krieger et al. (1991). The remaining sequences are shown, and sources indicated, in Figure 4 . Refer to Figure 4 for single- to triple-letter amino acid code conversions and for an explanation of the species abbreviations.

cysteines are structurally important. There are numerous additional fully conserved amino acid positions, and these may further suggest important structural conservation existing throughout the three OBP classes.

Comparisons in hydropathy between the $M$. sexta PBP, GOBP1, and GOBP2 are made in Figure 5. The three proteins appear generally similar. The most notable difference is that GOBPl is more hydrophobic in its C-terminal region than either GOBP2 or PBP, especially in the region surrounding amino acid 120. There are also slight differences betwecn all three proteins around amino acid 20, and again around amino acid 70 . The differences in hydrophobicity/hydrophilicity, together with the sequence differences, suggest that the three proteins are sufficiently unique to exhibit relative specificity in ligand binding. Quantitative and comparative ligand-binding studies between the three classes would be desirable.

Breer el al. (1990) have reported that a novel OBP, here identified as a GOBP2, was expressed solely in female antennal tissue of $A$. pernyi, based on probing of tissue RNA with OBP DNA by slot blot analysis. We have observed that the GOBP2s of five other species, including that of the sibling species $A$. polyphemus, were expressed in both male and female antennal tissue (Vogt et al., 1991). It is possible that $A$. pernyi represents a special case, and that GOBP2 expression in this species is sex specific. It may instead be the case, however, that the antennae of male $A$. pernyi, like those of the malc $A$. polyphemus (Bocckh et al., 1960), are so reduced in the number of sensilla for general olfaction that there was insufficient male GOBP2 mRNA in the Breer et al. (1990) experiment to detect. Tissue in situ analysis of the different sensilla classes on male and female antennae utilizing GOBP DNA probes could clarify this apparent discrepancy.

\section{Conserved sequences among certain $O B P$ signal peptides suggest coexpression and intracellular sorting}

In the context of evolution, the pressures that shaped the properties of the mature OBP proteins were and are fundamentally different than the pressures that shaped their signal peptides. The mature proteins evolved to interact with external chemical signals and to function in a behavioral context, while the signal peptides evolved to interact with intracellular signals involved in trafficking. Cytosolic signal recognition particles (SRPs) bind to signal peptides as they emerge from ribosomes, and then bind to specific protein receptors in the endoplasmic reticulum (ER) membrane to initiate protein translocation into the ER (reviewed by Rapoport, 1990). For homologous proteins expressed in the same general cell type, these intracellular signals might be expected to be conserved, especially within a given animal species, and the signal peptides might also be expected to be conserved. However, signal peptides are known to show little sequence conservation beyond their core hydrophobicity (Rapoport, 1990). Nevertheless, among the insect OBPs, the signal peptides are surprisingly well conserved within a given OBP class, but poorly conserved between classes in a given animal species (Fig. 6). This class conservation suggests that the OBP signal peptides might be involved in class-specific processing.

Both the GOBPs and PBPs are apparently represented by multiple classes. GOBP1 and GOBP2 were established as separate classes from $\mathrm{N}$-terminal sequence studies of proteins from six moth species (Vogt et al., 1991). Recently, a second PBP from $A$. pernyi was identified and sequenced (Krieger et al., 1991). The two $A$. pernyi PBPs are distinguished as APR-1 (Fig. 4, PBP, Aper) (Raming et al., 1990) and APR-2 (Krieger et al., 1991). APR-1 and APR-2 are about $85 \%$ identical in the mature proteins. Though similar, the two proteins apparently do not represent two alleles of the same gene, since the amino acid differences are nonrandom in position and are clustered to hydrophobic domains that are possibly involved in ligand binding (Krieger et al., 1991). The suggestion was made that APR-2 functions together with APR-1 to bind the respective pheromone components, an aldehyde and an acetate ester (Meng et al., 1989; Kricger et al., 1991). Thus, APR-1 and APR-2 presumably represent two distinct PBP classes in $A$. pernyi. Two distinct PBPs have also been identified in the gypsy moth $L$. dispar (Vogt et al., 1989, 1991).

Signal peptide sequences of seven insect OBPs are shown in Figure 6: those of the six OBPs indicated in Figure 4 plus APR-2 of $A$. pernyi. All of these OBPs are thought to be expressed in and secreted by glia-like support cells that ensheathe the sensory neuron somata and have highly folded apical membranes facing the sensillum lumen. The OBPs are presumably secreted across these apical membranes. The OBP signal peptides all contain hydrophobic cores of 10-12 amino acids flanked by more hydrophilic regions, characteristic of signals involved in protein translocation into ER for the purpose of secretion (von Heijne, 1986; Rapoport, 1990).

Two pairs of signal peptides show additional conservation in their sequences: those of the GOBP2s of $M$. sexta and $A$. pernyi and those of the PBPs of $A$. polyphemus and $A$. pernyi (APR1; Fig. 6). Comparisons of the two GOBP2s reveal the amino acid sequences LILM ( $M$. sexta) and LLLM (A. pernyi) as well as DSVMG (M. sexta) and DSVIG $(A$. pernyi). No such domain 
similarities are discernable between the three $M$. sexta signal sequences. Similar comparisons of the PBP signal peptides show that PBPs of $A$. polyphemus and $A$. pernyi (APR-1) are nearly identical and much different from the signals of the $M$. sexta PBP or the second $A$. pernyi PBP (APR-2). The near identity of the two Antheraea PBPs (0.90) compared with the dissimilar $M$. sexta PBP $[0.23$ with either $A$. polyphemus PBP or $A$. pernyi (APR-1)] might be explained solely by the relative phyletic relatedness of these three species. However the very different signal peptide of the $A$. pernyi $\Lambda \mathrm{PR}-2$ requires an alternative explanation. Apparently, evolutionary selective pressures have acted on these signal peptides to retain conservation within a given OBP class. Perhaps these signal peptides contain information for differential intracellular processing among the respective PBP and GOBP classes.

We have previously suggested that GOBPl and GOBP2 might be expressed in distinctly different general-olfactory sensilla (Vogt et al., 1991). However, comparative analysis of the OBP signal peptides suggests that the signal peptides might be involved in differential processing of the OBP classes, and such differential processing suggests that different OBPs are coexpressed. Certainly there are separate sex pheromone- and general odorantsensitive sensilla classes, with PBPs associating with one class and GOBPs associating with the other (Vogt et al., 1991). However, specific classes of olfactory sensilla may contain multiple classes of the appropriate OBPs. In this context, conserved signal peptides could ensure that coexpressed OBPs would be directed toward different ER so that independent control could be maintained for subsequent processing and secretion of each OBP. For example, since the OBPs may exist as protein dimers (De Kramer and Hemberger, 1987), independent control might be important to regulate correct homodimerization versus heterodimerization. Another indication of differential regulation of the OBP classes is the in-class conservation of the peptidase cleavage sites, where the signal-side amino acid of each site is constant within an OBP class but different between classes (Fig. 6 ). The class-distinct sites might indicate that different peptidases are utilized or that cleavage rates are different for respective classes.

\section{Variation among PBPs, GOBPIs, and GOBP2s: functional significance}

Our findings show that the PBPs are variable while the respective GOBPs are highly conserved. Based on these different variation patterns, we suggested functional roles for the respective insect OBPs (Vogt et al., 1991). The variation in the PBPs was consistent with their association with sex pheromone-specific neurons. Each species utilizes a different sex pheromone, and thus the PBP of each species has evolved to be different in a context of processing species unique odorants. In contrast, the GOBPs of the same species are all nearly identical, suggesting that the GOBPs all share a common ligand. Because the GOBPs associate with general-odorant neurons, this common ligand is interpreted to be a common pool of general odorants. Furthermore, because there are two GOBPs, GOBP1 and GOBP2, we suggested that they might interact with two distinct classes of general odorants.

The different classes of OBP define separate sensory pathways in the insect olfactory system: the PBPs associate with sex pheromone-specific neurons, while the GOBPs associate with general odorant-sensitive neurons (Vogt et al., 1991). It may be that GOBP1 and GOBP2 also define separate general-odorant sensory pathways by being expressed in distinctly different sensilla, as suggested by Vogt et al. (1991). However, analysis presented here of signal peptides belonging to several OBPs suggests that GOBP1 and GOBP2 may be coexpressed by the same cells and hence in the same sensilla. A similar situation may exist for two PBPs of $A$. pernyi (APR-1 and APR-2; Krieger et al., 1991). In either case, coexpression or not, the OBPs are situated between the external environment and the sensory neurons and therefore represent the initial biochemical step in odor detection in these animals. We have suggested that the OBPs act in part as odorant filters, peripheral to the receptor neurons, limiting which kinds of molecules have access to the receptors (Vogt et al., 1991). This suggestion was based on the existence of multiple OBP classes within a given animal species and the presumption that respective OBPs possess different ligand-binding specificities, suggested by sequence and hydrophobicity differences. However, if the OBPs do act as filters, the nature of these filters would be different depending on whether or not OBPs are coexpressed.

If OBPs are all individually expressed in distinctly different sensilla, their filtering properties might ensure that only a restricted set of odorants would be solubilized into the sensillum fluid and subsequently gain access to the receptor neurons. In contrast, if OBPs are coexpressed, their individual odorantbinding specificities might complement and ensure that a broader class of odorants would have access to the receptor neurons. In the case of coexpression, odorant detection would be enhanced rather than restricted. This could be clarified by immunohistological or tissue in situ studies and ligand-binding studies. Nevertheless, there remains a fundamental difference between the PBPs and the GOBPs. The PBPs evolved only to be effective at processing a very narrow group of odorant molcculcs, the species-specific sex pheromones. In contrast, the GOBPs evolved to be effective at processing a very broad group of general odorants, and based on the interspecies conservation of the GOBPs, these general odorants were of common importance.

The interspecies conservation of the GOBPs has implications concerning our understanding of the life history of these animals. The various moth species in the study utilize quite different habitats. For example, $M$. sexta feed and deposit eggs only on tobacco plants; $B$. mor $i$ feed specifically on mulberry leaves; $L$. dispar live in deciduous forests throughout the northern hemisphere; $O$. pseudotsugata live only in coniferous forests of the northwestern United States and southwestern Canada; yet the GOBPs of all these species have nearly identical sequences (Vogt et al., 1991), suggesting that these animals are equally receptive to the same odorants irrespective of odorant habitat. In the coursc of evolution, the influences of odorant habitat on natural selection of the olfactory system might have been expected to induce specificity at the detection level. However, the high conservation of the GOBPs suggests that these olfactory systems have been selected instead to be broadly sensitive to all odorants. These observations suggest that, if habitat selection by odor cue exists, its mechanism most likely resides entirely in the brain, presumably at the level of the olfactory lobe (Boeckh et al., 1987).

Odorant-binding proteins may represent one of many molecular adaptations to terrestrial life. The presence of nonhomologous OBPs in vertebrates versus insects (Gyorgyi et al., 1988; Raming et al., 1989, 1990; Breer et al., 1990) is consistent with terrestrialization occurring independently in these two groups 
and indicates that the OBPs of the two groups are the result of convergent evolution. A third group, terrestrial gastropods, may also possess an independently evolved OBP system. The olfactory epithelium of the African land snail Achatina fulica is covered with a proteinaceous fluid distinctly different from the mucus covering the rest of the animal, and it has been suggested that this proteinaceous fluid might aid in odorant capture (Chase, 1986). An aspect that is unique to the insects and other arthropods is that their olfactory neurons are compartmentalized by the cuticular sensilla. This compartmentalization has apparently allowed for different olfactory pathways to become specialized in different sensilla classes. In the general-olfactory pathway, conservation of GOBPs suggests that the periphery may be broadly tuned, and that odor discrimination occurs primarily in the brain. In the sex-pheromone pathway, however, the species uniqueness of PBPs indicates that odor discrimination is occurring in the periphery, and that the initial biochemical steps in odor detection may have a profound role in odor perception.

\section{References}

Birnstiel ML, Busslinger M, Strub K (1985) Transcription termination and 3' processing: the end is in site! Cell 41:349-359.

Boeckh J, Kaissling K-E, Schneider D (1960) Sensillin und Bau der Antennengeissel von Telea polyphemus (Verleiche mit weiteren Saturniden: Antheraea, Platasamia, und Philosamia). Zool J Anat 78: 559-584.

Boeckh J, Ernst K-D, Selsam P (1987) Neurophysiology and neuroanatomy of the olfactory pathway in the cockroach. Ann NY Acad Sci 510:39-43.

Breer H, Krieger J, Raming K (1990) A novel class of binding proteins in the antennae of the silk moth Antheraea pernyi. Insect Biochem 20:735-740.

Carr WES, Gleeson RA, Trapido-Rosenthal HG (1990) The role of perireceptor events in chemosensory processes. Trends Neurosci 13: 212-215.

Chamberlain JP (1979) Fluorographic detection of radioactivity in polyacrylamide gels with the water-soluble fluor, sodium salicylate. Anal Biochem 98:132-135.

Chase R (1986) Lessons from snail tentacles. Chem Senses 11:411426.

Chomczynski P, Sacchi N (1987) Single-step method of RNA isolation by acid guanidinium thiocyanate-phenol-chloroform extraction. Anal Biochem 162:156-159.

Davis LG, Dibner MD, Battey JF (1986) Basic methods in molecular biology, pp 139-142. New York: Elsevier.

De Kramer JJ, Hemberger J (1987) The neurobiology of pheromone reception. In: Pheromone biochemistry (Prestwich GD, Blomquist GL, eds), pp 433-472. Orlando: Academic.

Gubler U, Hoffman BJ (1983) A simple and very efficient method for generating cDNA libraries. Gene 25:263-547.

Gyorgyi TK, Roby-Shemkovitz AJ, Lerner MR (1988) Characterization and cDNA cloning of the pheromone-binding protein from the tobacco hornworm, Manduca sexta: a tissue-specific developmentally regulated protein. Proc Natl Acad Sci USA 85:9851-9855.

Keil TA (1984) Reconstruction and morphometry of silkmoth olfactory hairs: a comparative study of sensilla trichodea on the antennae of male Antheraea polyphemus and Antheraea pernyi (Insecta, Lepidoptera). Zoomorphology 104:147-156.

Keil TA (1989) Fine structure of the pheromone sensitive sensilla on the antenna of the hawkmoth, Manduca sexta. Tissue Cell 21:139151.

Klein U (1987) Sensillum-lymph proteins from antennal olfactory hairs of the moth Antheraea polyphemus (Saturniidae). Insect Biochem 17:1193-1204

Kochansky J, Tette J, Tashenberg EF, Carde RT, Kaissling KE, Roelofs WL (1975) Sex pheromone of the moth Antheraea polyphemus. J Insect Physiol 21:1977-1983.

Kraft R, Tardiff J, Krauter KS, Leinwand LA (1988) Using mini-prep plasmid DNA for sequencing double standard templates with Sequenase $^{\mathrm{TM}}$. BioTechniques 6:544-547.
Krieger J, Raming K, Breer H (1991) Cloning of genomic and complementary DNA encoding insect pheromone binding proteins: evidence for microdiversity. Biochim Biophys Acta 1088:277-284.

Kyte J, Doolittle RF (1982) A simple method for displaying the hydrophobic character of a protein. J Mol Biol 157:105-132.

Laemmli UK (1970) Cleavage of structural proteins during assembly of the head of bacteriophage T4. Nature 227:680-685.

Lee K-H, Wells RG, Reed RR (1987) Isolation of an olfactory cDNA: similarity to retinol-binding protein suggests a rolc in olfaction. Science 235:1053-1056.

Maniatis T, Fritsch EF, Sambrook J (1982) Molecular cloning, a laboratory manual. Cold Spring Harbor, NY: Cold Spring Harbor Laboratory.

Meng LZ, Wu CH, Wicklein M, Kaissling K-E, Bestmann HJ (1989) Number and sensitivity of three types of pheromone receptor cells in Antheraea pernyi and A. polyphemus. J Comp Physiol A 165:139146.

Pelosi P, Baldaccini NE, Pisaanelli AM (1982) Identification of a specific olfactory receptor for 2-isobutyl-3-methoxypyrazine. Biochem J 201:245-248.

Pelosi P, Maremmani C, Muratorio A (1990) Purification of an odorant binding protein from human nasal mucosa. In: NATO ASI Series $\mathrm{H}, \mathrm{Vol} 39$, Chemosensory information processing (Schild D, ed), pp 125-130. Berlin: Springer.

Pevsner J, Hwang PM, Sklar PB, Venable JC, Snyder SH (1988a) Odorant-binding protein and its mRNA are localized to lateral nasal gland implying a carrier function. Proc Natl Acad Sci USA 85:23832387.

Pevsner J, Reed RR, Feinstein PG, Snyder SH (1988b) Molecular cloning of odorant-binding protein: member of a ligand carrier family. Science 241:336-339.

Raming K, Krieger J, Breer H (1989) Molecular cloning of an insect pheromone-binding protein. FEBS Lett 256:215-218.

Raming K, Krieger J, Breer H (1990) Primary structure of a pheromone-binding protein from Antheraea pernyi: homologies with other ligand-carrying proteins. J Comp Physiol B 160:503-509.

Rapoport TA (1990) Protein transport across the ER membrane. Trends Biochem Sci 15:355-358.

Rybczynski R, Reagan J, Lerner MR (1989) A pheromone-degrading aldehyde oxidase in the antennae of the moth Manduca sexta. $\mathrm{J}$ Neurosci 9:1341-1353.

Rybczynski R, Vogt RG, Lerner MR (1990) Antennal-specific pheromone-degrading aldehyde oxidases from the moths Antheraea polyphemus and Bombyx mori. J Biol Chem 32:19712-19715.

Saiki RK, Scharf S, Faloona F, Mullis KB, Horn GT, Erlich HA, Arnheim N (1985) Enzymatic amplification of the $\beta$-globin genomic sequences and restriction site analysis for diagnosis of sickle cell anemia. Science 230:1350-1354.

Sanger F, Nicklen S, Coulsen AR (1977) DNA sequencing with chainterminating inhibitors. Proc Natl Acad Sci USA 74:5463-5467.

Sheets MD, Ogg SC, Wickens MP (1990) Point mutations in AAUAAA and the poly(A) addition site: effects on the accuracy and efficiency of cleavage and polyadenylation in vitro. Nucleic Acids Res 18:57995805 .

Steinbrecht RA, Gnatzy W (1984) Pheromone receptors in Bombyx mori and Antheraea pernyi. I. Reconstruction of the cellular organization of the sensilla trichodea. Cell Tissue Res 235:25-34.

Vogt RG (1987) The molecular basis of pheromone reception: its influence on behavior. In: Pheromone biochemistry (Prestwich GD, Blomquist GL, eds), pp 385-431. Orlando: Academic.

Vogt RG, Riddiford LM (1981a) Pheromone deactivation by antennal proteins of Lepidoptera. In: Insect development and behaviour (Sehnal F, Zabza A, Menn JJ, Cymborowski B, eds), pp 955-967. Wroclaw, Poland: Polytechnical University of Wroclaw.

Vogt RG, Riddiford LM (1981b) Pheromone binding and inactivation by moth antennae. Nature 293:161-163.

Vogt RG, Riddiford LM (1986) Pheromone reception: a kinetic equilibrium. In: Mechanisms in insect olfaction (Payne TL, Birch MC, Kennedy EJ, eds), pp. 201-208. Oxford: Clarendon.

Vogt RG, Riddiford LM, Prestwich GD (1985) Kinetic properties of a pheromone degrading enzyme: the sensillar esterase of Antheraea polyphemus. Proc Natl Acad Sci USA 82:8827-8831.

Vogt RG, Prestwich GD, Riddiford LM (1988) Sex pheromone receptor proteins, visualization using a radiolabeled photoaffinity analog. J Biol Chem 8:3952-3959. 
Vogt RG, Kohne AC, Dubnau JT, Prestwich GD (1989) Expression of pheromone binding proteins during antennal development in the gypsy moth Lymantria dispar. J Neurosci 9:3332-3346.

Vogt RG, Rybczynski R, Lcrncr MR (1990) The biochemistry of odorant reception and transduction. In: NATO ASI Series H, Vol 39, Chemosensory information processing (Schild D, ed), pp 33-76. Berlin: Springer.
Vogt RG, Prestwich GD, Lerner MR (1991) Odorant-binding-protein subfamilies associate with distinct classes of olfactory receptor neurons in insects. J Neurobiol 22:74-84.

von Heijne $G$ (1986) A new method for predicting signal sequence cleavage sites. Nucleic Acids Res 14:4683-4690.

Wickens $M$ (1990) How the messenger got its tail: addition of poly(A) in the nucleus. Trends Biochem Sci 15:277-281. 